\title{
SMART CITY DYNAMIC DASHBOARD: ALTERNATIF KOLABORASI MULTI APLIKASI PADA SMART CITY MENGGUNAKAN METODE USER- DRIVEN COLLABORATION (UDC)
}

\author{
Agit Amrullah \\ Informatika, Universitas AMIKOM Yogyakarta \\ Jl. Ring Road Utara, Condong Catur, Sleman, Yogyakarta 55283 \\ Email:agit@amikom.ac.id
}

\begin{abstract}
Abstrak
Pembangunan aplikasi smart city dikembangkan dengan berbagai metode dengan tujuan agar aplikasi dapat dipergunakan secara maksimal dalam menunjang keberlangsungan smart city pada suatu kota. Aplikasi yang beragam dengan kuantitas semakin meningkat, disesuaikan dengan kebutuhan dalam penyelesaian masalah pada suatu kota cerdas menimbulkan permasalahan baru dalam memanajemen aplikasiaplikasi smart city. Masalah manajemen aplikasi pada stakeholder level top management memiliki permasalahan lain baik dalam regulasi, sosialisasi dan kolaborasi dengan instansi terkait serta pemangku kepentingan lain dalam pengembangan aplikasi smart city. Pada penelitian ini, dikembangkan sebuah framework di dalam memanajemen aplikasi-aplikasi smart city dengan nama Smart City Dynamic Dashboard (SCDD), dengan harapan aplikasi yang dikembangan pada smart city dapat meningkat pada experience, awarness, efisiensi dan efektifitas aplikasi smart city yang beragam pada suatu kota.
\end{abstract}

Kata Kunci: aplikasi, smart city, user driven collaboration.

\section{Pendahuluan}

Masyakat teknologi bertransformasi dari ketersediannya informasi menjadi berkebutuhan informasi yang mudah diakses, cepat, tepat, serta akurat pada berbagai teknologi informasi dan komunikasi [1]. Tuntutan pembangunan mulai muncul pada kota yang diinginkan masyarakat dapat layak huni, aman, nyaman, hijau berketahanan iklim dan bencana, berbasis pada karakter fisik, keunggulan dalam bidang ekonomi, berdaya asing, budaya lokal, hingga berbasis teknologi dan IT [2]. Kebutuhan inilah yang mendorong para stakeholder untuk menyelesaikan permasalahan-permasalahan pada kota dengan memanfaatkan teknologi baik pada level top management hingga low level management. Konsep Smart City atau kota cerdas menggunakan pemanfaatan teknologi informasi untuk memaksimalkan sumber daya dengan maksud memberikan pelayanan yang efektif dan efisien kepada warga kota. Konsep ini memiliki koneksi terintegrasi pada berbagai bidang sehingga memberikan dampak yang praktis dan efisiensi dalam hal pengelolaan kota [3]. Smart city muncul pada saat terjadinya urbanisasi dan mendorong baik warga, perencana kota, pengembang, pelaku bisnis, dan pemerintah untuk melihat kembali penyelesaian permasalahanpermasalahan pada kota dengan melalui suatu visi, kota yang "cerdas".

Model konsep smart city dipresentasikan pertama kali pada tahun 2005 di Dubai oleh perusahaan Cisco [4], yang didalamnya mengimplementasikan Smart Government, Smart Media City, Healthcare City, dan Knowlegde Village. Pada tahun 2009 kota New York dan Amsterdam mengembangkan konsep smart city dengan menghadirkan aplikasi smart city diantaranya : Smarter Healthcare, Smarter Transportation, Smarter Public Safety, Smarter Energy \& Utilities, Smarter Education, dan Smarter Government Services [5]. Perkembangan aplikasi smart city terus berkembang berbanding lurus dengan tantangan pada dimensi dari smart city itu sendiri. Dimensi smart city tidak terlepas dari komponen utamanya, yang diantaranya adalah teknologi, masyarakat, dan institusi akan memimpin perkembangan smart city secara komperhensif [6].

Menurut Liu pada Su. [7], arsitektural Smart city terdiri dari lapisan persepsi (perception layer) yang berfungsi dalam identifikasi objek dan mengumpulkan informasi melalui berbagai sensor, jaringan (network) yang berfungsi dalam transmisi dan pemrosesan informasi pada komunikasi serta manajemen jaringan pada pusat pemrosesan data dan informasi, dan aplikasi (application) yang berfungsi pada analisa dan memroses data yang besar (big data) melalui cloud computing dan teknologi kecerdasan, untuk mewujudkan interkoneksi dan interoperabilitas pada kota cerdas. Arsitektur inilah yang akan menjadi landasan trend smart city untuk dikembangkan pada lingkungan urban.

Pada konstruksi smart city, aplikasi merupakan salah satu landasan yang terpenting dan menghasilkan perhatian besar di dalamnya [7]. Gambar 1 menunjukkan bagaimana aplikasi memiliki hubungan pada konstruksi platform smart city.

Beberapa kendala pada penerapan aplikasi pada smart city adalah pada faktor investasi [3], infrastruktur yang masih minimum [8], tidak mudahnya aplikasi untuk digunakan dalam masyarakat [9], belum munculnya kebutuhan bisnis pada internal dan eksternal organisasi [10], pengendalian regulasi pada semua elemen perkotaan [11]. Beberapa hal ini lah yang mendorong proses transformasi aplikasi pada smart city dilakukan dengan perbaikan-perbaikan pada sektor krusial dan secara efektif maupun efisien. Kerja sama dilakukan pemerintah pada pengembangan aplikasi smart city, sebagai contoh pada proyek smart city di Kota Bandung dengan kolaborasi perusahaan ternama, Telkom, menjadi 
kerja sama perusahaan ICT dengan bentuk public-private partnership collaboration [12] yang pada tahun 2017 menghasilkan setidaknya 394 aplikasi dalam mendukung kegiatan pada Satuan Kerja Perangkat Daerah (SKPD) serta mempermudah pelayanan publik di Kota Bandung [13].

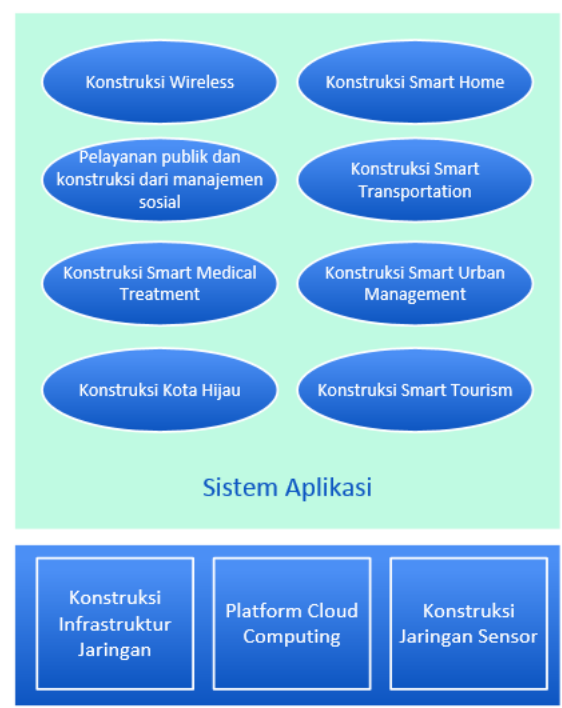

Gambar 1. Konstruksi Sistem Aplikasi pada Smart City

Kesadaran yang kuat, mengedukasi, dan aspek kepemimpinan dalam pelayanan masyarakat dapat menyingkirkan permasalahan yang ada pada penerapan smart city [14]. Pembangunan aplikasi smart city yang fleksibel, efektif, efisien, dapat menyelesaikan permasalahan perkotaan, dan bagaimana menciptakan smart people menjadi tantangan pada pengembangannya. Kontruksi aplikasi yang menjadi salah satu peranan penting pada pengembangan smart city menjadikannya sebagai iterasi dalam smart people agar dapat dielaborasikan pada pembangunan smart city secara maksimal.

Program smart city masih sangat diperlukannya sosialisasi kepada masyarakat terutama pada program yang masih baru, dikarenakan masyarakat belum sepenuhnya mengetahui mengenai program pemerintah [15]. Publikasi pemerintah kota yang dilakukan kepada masyarakat saat ini hanya sebatas dilakukan oleh humas dengan strategi publikasi, community involved, dan special event [16].

Efektivitas Decision Support Systems (DSS) dapat dibangun pada group individual pada struktur pembeda prioritas, keahlian, dan perspektif dengan kolaborasi intelegen dan analisa [17]. Kolaborasi developer to developer dipergunakan pemerintah didalam pengembangan berbasis adopsi dan kontribusi dengan menggunakan metode User-Driven Collaboration (UDC) dalam kontribusi author dan komponen yang ada di dalamnya dapat meningkatkan efektifitas pengembangan [18].

Mengacu kepada kebutuhan konstruksi aplikasiaplikasi smart city yang diperlukannya perhatian yang intensif karena semakin banyaknya aplikasi dalam mendukung keberlangsungan ekosistem smart city pada suatu kota, maka diperlukannya sebuah alternatif dalam pengembangan aplikasi smart city. Pada penelitian ini diusulkan alternatif dalam konstruksi pengembangan aplikasi smart city menggunakan metode User-Driven Collaboration (UDC) dan pegembangan framework Smart City Initiative Design (SCID) dan menghasilkan terminal (dashboard) untuk aplikasi yang dikembangkan pada smart city dengan harapan agar dapat meningkatkan experience, awarness, dan efektifitas aplikasi smart city yang beragam pada suatu kota.

\section{Metode}

Penelitian ini adalah penelitian deskriptif dengan dilakukan pendekatan kualitatif pada arah kebijakan pengembangan aplikasi smart city dengan menggunakan pendekatan User-Driven Collaboration (UDC). Penelitian ini bertujuan untuk mendeskripsikan, menganilisis, dan menginterprestasikan kondisi pengembangan aplikasi pada smart city saat ini dengan pengembangan pada manajerial aplikasi pada smart city menggunakan model usulan bernama Smart City Dynamic Dashboard melalui pendekatan metode UserDriven Collaburation (UDC).

Lingkup penelitian adalah government sebagai stakeholder dalam penentu kebijakan manajemen pengembangan aplikasi smart city. Tahapan yang akan dilakukan adalah studi literatur pada pengembangan aplikasi smart city dan kebijakan serta platform yang dipergunakan yang nantinya akan mengacu indikator pengembangan smart city, dengan model pada Garuda Smart City framework [19] yang mengacu resource pada smart infrastructure, technology \& environment untuk melihat representasi pengembangan aplikasi smart city pada level tertentu, dan penerapan pengembangan aplikasi menggunakan framework Smart City Dynamic Dashboard.

\section{Hasil dan Pembahasan}

Pada studi literatur yang dilakukan, penelitian yang dilakukan oleh Santana et al. [20], dalam mengaplikasikan teknologi pada smart city setidaknya terdapat 4 elemen didalamnya : internet of thigs, big data, cyber physical system, dan cloud computing. Sedangkan pada Lee et al. [21] menjelaskan teknologi yang harus dikerjakan pada smart city memenuhi 5 kriteria, yang diantaranya adalah sensing, processing, network, interface, dan security. Teknologi pada smart city akan memberikan koleksi data yang saling terhubung dengan jumlah yang besar tergantung dari kompleksitas teknologi yang dibangun pada setiap elemen teknologi smart city. Pada aspek lain, data yang ada pada smart city adalah bersifat open access secara fundamental, dan dapat diakses pada masyarakat, perusahaan, dan organisasi pada multi disiplin data dengan harapan ekosistem inovasi dapat terwujud dalam menyelesaikan permasalahan-permasalahan yang terdapat pada suatu kota [22]. Hubungan antara keduanya dapat digambarkan pada Gambar 2. 


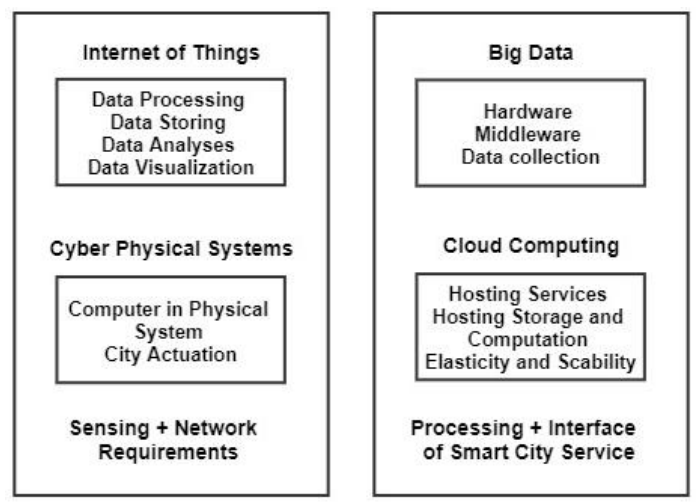

Gambar 2. Gambaran platform teknologi pada smart city

Kebutuhan fungsional dalam mengembangakan teknologi smart city dititik-beratkan pada manajemen data dan akses data melalui API [20]. Pada gambar 3 diperlihatkan bahwasanya hubungan kebutuhan dan penerapan teknologi pada smart city memiliki hubungan pada masing-masing penerapan teknologi yang dibutuhkan, sebagai contoh pada penerapan big data yang akan meng-handle pada manajemen data dan data processing, maka cloud computing akan memanajemen pada platform manajemen service dan ekternal data yang dapat diakses melalui API, maka pada hubungan kebutuhan dan penerapan teknologi dapat digambarkan kebutuhan sumber daya apasaja yang dibutuhkan pada pengembangan aplikasi smart city.

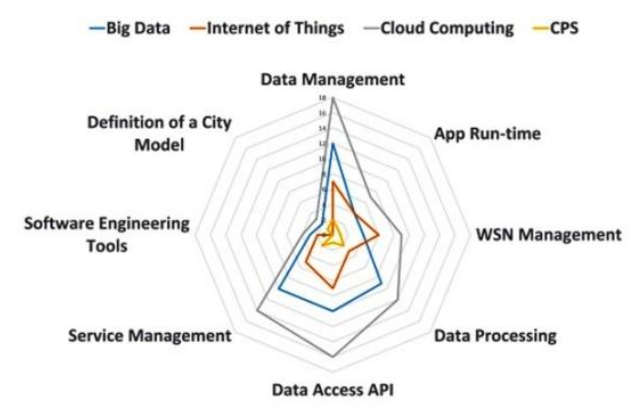

Gambar 3. Hubungan kebutuhan dan penerapan teknologi pada smart city [20]

Open Labs: solusi alternatif pengembangan aplikasi smart city

Pengembangan aplikasi pada smart city dikerjakan secara kompetitif sesuai dengan kebutuhan inovasi yang dikembangkan. Habitat pada perkotaan memiliki multi disiplin organisasi di dalam menunjang fasilitas yang dibutuhkan masyarakat perkotaan yang pada umumnya dikelola oleh pemerintah kota baik pada level administrasi hingga decision support. Dengan keterbatasan sumber daya manusia yang dimiliki, pemerintah dapat melakukan investasi pada periset, pengembang, dan proyek inovasi di dalam menyelesaikan permasalahan perkotaan dengan menggunakan dukungan dari living labs [23]. Pengembangan aplikasi dengan menggunakan dukungan dari living labs, akan memberikan dampak diversiasi produk dengan harapan aplikasi dapat memiliki lifetime yang panjang, karena prinsip dari User-Driven Innovation (UDI) melibatkan end-user sebagai partisipan secara langsung didalam pengumpulan kebutuhan terhadap masalah, user test, hingga saran dan solusi yang didapatkan dari masyarakat perkotaan secara langsung.

\section{Open data: kolaborasi pemerintah, pengembang, dan masyarakat}

Strategi open data telah berkembang pada smart city sebagai salah satu elemen pada smart city, menurut Ojo et.al [24], memiliki harapan dengan kompleksitas permasalahan dapat ditekan dengan inisiatif data terbuka (open data) sehingga para pengembang dapat berkontribusi dan diharapkan dapat memberikan keuntungan pada manajemen perkotaan. Namun pada penerapannya, konsep open data memiliki permasalahan tersendiri kepada para pemangku kepentingan di perkotaan, pada gambar 4 diperlihatkan solusi bagaimana cara menghubungkan pengembang smart city dengan dampak output keluaran pengembangan pada smart city dan bagaimana mengatasi stakeholder pada transformasi level tertentu dengan menggunakan framework Smart city initiative Design (SCID).



Gambar 4. Smart City Initiative Design Framework (SCID) [25]

Pada gambar 4 digambarkan terdapat 6 elemen dalam SCID framework, Critical success factors yang dimaksudkan adalah pada kondisi dan kontribusi yang signifikan dengan kesuksesan inovasi smart city. Pada tantangan permasalahan dihadapkan pada pembuatan regulasi peraturan daerah/kota dengan mekanisme peraturan pemerintah yang ada. Masyarakat, pengembang dan periset atau dapat dikatan sebagai inisiator smart city, akan mengembangkan proyek yang berhubungan dengan smart city atau implementasi aplikasi dengan menghasilkan output inovasi smart city yang berhubungan dengan proyek atau aplikasi yang diimplementasikan. Domain peraturan daerah/kota berkaitan dengan peraturan yang memiliki dampak pada inovasi smart city yang dikembangkan. Stakeholder dan output/hasil transformasi kota yang diharapkan adalah pada keseluruhan kota dan hasil yang diinginan oleh para pemangku kepentingan yang lebih luas.

\section{Smart City Dynamic Dashboard}

Kolaborasi dalam pengembangan aplikasi-aplikasi pada smart city dimanfaatkan dalam efektifitas dan efisiensi pengembangan pada tahap baik perencanaan, konstruksi 
baris kode, hingga User Acceptance Test (UAT). Kolaborasi yang melibatkan masyarakat, pengembang, pemerintah, dan teknologi diimplementasikan pada Smart City Dynamic Dashboard (SCDD) Framework yang dapat dilihat pada Gambar 5.

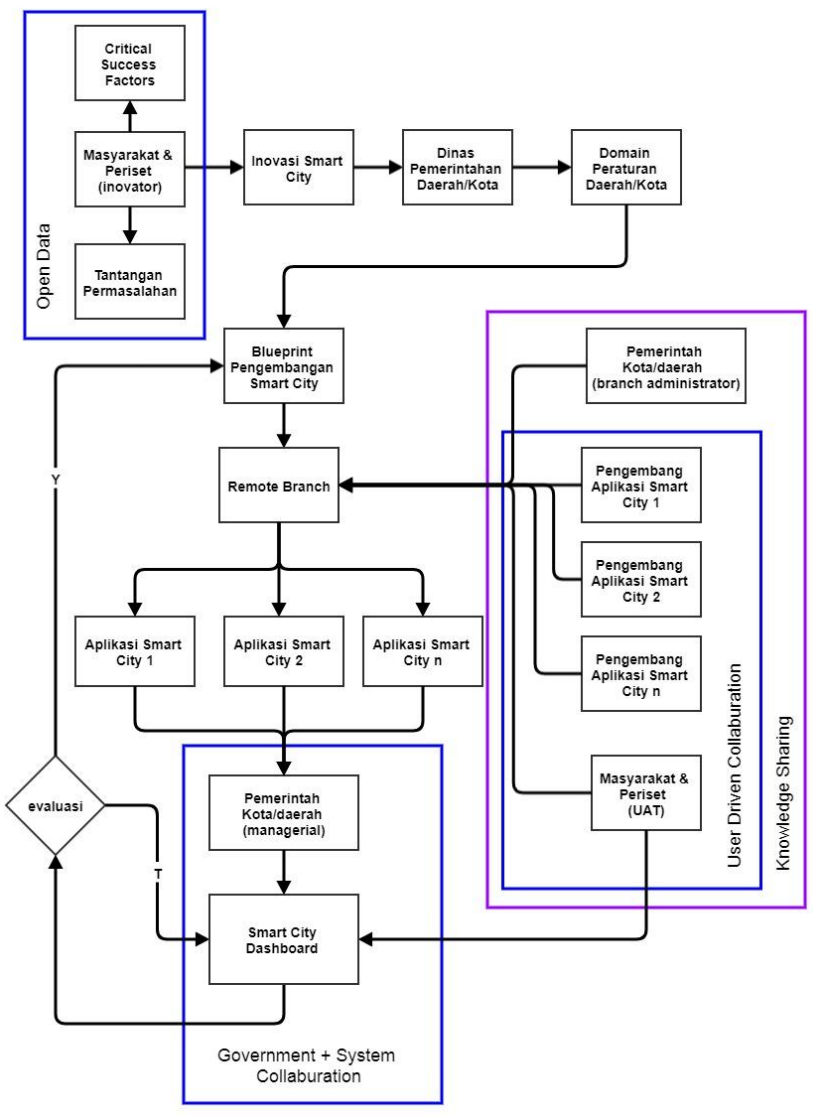

Gambar 5. Smart City Dynamic Dashboard (SCDD) Framework

Framework SCDD dalam pengembangan aplikasiaplikasi smart city memiliki batasan-batasan sesuai dari pemangku kepentingan dan regulasi peraturan kota/daerah dimana aplikasi smart city akan dikembangkan. Pada gambar 6 dapat dilihat bahwasanya framework SCDD dapat dipergunakan dengan batasan kolaborasi baik pengembang, masyarakat, dan peneliti secara terbatas dikarenakan peraturan yang mengikat serta regulasi yang ada pada suatu daerah/kota. Dalam setiap pengembangan yang dilakukan perlu dilakukan dokumentasi pengembangan dan batasan pada sharing knowledge baik pada kolurasi pengembang, masyarakat, dan peneliti kepada pemerintah kota ataupun sebaliknya. Batasan yang dimaksud adalah pada pemangku kepentingan dapat melakukan open data dan pada kolaborasi pengembang, masyarakat, dan peneliti dapat membangun open labs sebagai media di dalam pengembangan aplikasi-aplikasi smart city dikembangkan. Dengan kolaborasi yang aktif dan dukungan pemerintah, aplikasi-aplikasi smart city akan dipublikasikan dengan melalui regulasi dan persetujuan dari pemerintah kota atau dinas terkait dengan terminal aplikasi atau smart city dashboard sercive sesuai pada hasil output akhir pada framework SCDD.

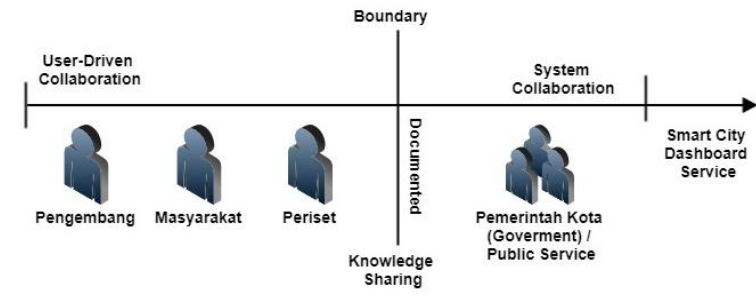

Gambar 6. Smart City Dynamic Dashboard (SCDD) collaburation service

\section{Collaburative Workflow}

Smart City Dynamic Dashboard (SCDD) yang dapat dilihat pada gambar 5, memfasilitasi pengembangan aplikasi pada smart city dengan melibatkan stakeholder pada smart city melalui kolaborasi aktif dengan pengembang aplikasi berbasis komunitas dan penciptaan smart development pada smart city. Dasar regulasi pembangunan aplikasi dibangun menggunakan framework dari Smart City Initiative Design (SCID) sebagai penghubung dari para pemangku kepentingan dengan masyarakat dan periset (inovator) dari aplikasi smart city yang akan dikembangkan.

Pengembangan aplikasi-aplikasi smart city dengan menggunakan framework SCDD, dirancang dengan menggunakan blueprint sebagai acuan pengembangan yang mengacu kepada regulasi peraturan kota/daerah dimana aplikasi-aplikasi smart city akan dikembangkan. Dalam hal ini, dinas pemerintah kota/daerah turut serta aktif di dalam pengembangannya dengan menyesuaikan dari lingkup aplikasi yang sedang dikembangkan, dinas pemerintah kota/daerah juga sebagai eksekutor pada ijin aplikasi akan dikembangkan atau diteruskan kepada dinas terkait lainnya.

Pengembangan aplikasi akan dimulai setelah blueprint awal disetujui atau direvisi oleh para pemangku kepentingan. Blueprint yang dihasilkan akan disimpan dalam repositori secara awan (cloud), dengan memperhatikan keamanan dalam informasi yang diberikan namun data akan dibagi secara terbuka oleh masyarakat, periset, dan pengembang. Data yang dimaksudkan adalah data yang bersifat dummy dipergunakan dalam melakukan testing atau riset data dari para peneliti.

Pengembang aplikasi dapat aktif berkontribusi secara awan (cloud service) dengan sebuah manajemen kode pemograman berbasis branch account yang dapat diakses secara terbuka oleh pengembang, masyarakat, maupun peneliti, namun untuk eksekutor pada luaran kode program aplikasi smart city yang akan digunakan, dieksekusi oleh seorang administrator branch yang ditunjuk oleh super administrator branch. Masyarakat dan peneliti juga dapat berperan dalam memberikan masukan pengembangan aplikasi smart city yang dibangun dengan menggunakan konsep open data dan open labs pada tahapan ini.

Aplikasi yang telah dikembangkan akan dibangun sebuah "terminal" sebagai jalan dalam menjalankan aplikasi-aplikasi yang mendukung smart city. Terminal inilah yang akan menjadi jalur utama pada seluruh aplikasi-aplikasi smart city yang tersedia dalam suatu 
kota/daerah sehingga diharapkan dapat meningkatkan dalam data informasi yang terpusat dan kesadaran dalam penggunaan aplikasi masyarakat perkotaan dengan bentuk dashboard yang memiliki akses aplikasi all in one of smart city application.

\section{Kesimpulan}

Penelitian ini, pembangunan smart development pada aplikasi- aplikasi smart city dengan melihat dari hubungan para pemangku kepentingan, masyarakat, dan pengembang termasuk regulasi peraturan pemerintah dalam setiap pengembangan aplikasi-aplikasi smart city. Melihat dari pengembangan aplikasi smart city yang ada, potensi untuk pengembangan aplikasi yang terpusat dapat dilakukan dengan harapan banyaknya aplikasi smart city dalam suatu kota/daerah dapat disosialisasikan kepada masyarakat dengan cepat dan diharapkan dapat meningkatkan open innovation environment pada pengembangan aplikasi-aplikasi smart city di masa kini. Framework Smart City Dynamic Dashboard (SCDD) diharapkan dapat menjawab tantangan pada open innovation environment pengembangan aplikasi-aplikasi smart city. Untuk itu perlu dilakukan studi fesiability pada framework SCDD ini lebih lanjut pada penelitian berikutnya.

\section{Daftar Pustaka}

[1] N. Widodo, "Pengembangan e-Government di Pemerintahan Daerah Dalam Rangka Mewujudkan Smart City (Studi di Pemerintah Daerah Kota Malang)," vol. 2, no. 4, p. 9, 2016.

[2] M. E. B. Conoras and N. K. Hikmawati, "Smart City Peluang Dan Tantangan Untuk Papua Bangkit, Mandiri Dan Sejahtera," p. 6, 2018.

[3] S. Hidayatulloh, "Internet of Things Bandung Smart City," J. Inform., vol. 3, p. 12, Sep. 2016.

[4] Abdulhakin Malik, "Dubai The Smart City," presented at the https://www.cisco.com/web/learning/le21/le34/dow nloads/689/nobel/2005/docs/Abdulhakim_Malik.pd f, Dubai, Dec-2005.

[5] "New York 2009: Smart Cities," https://www.ibm.com/smarterplanet/us/en/smarter_ cities/article/newyork2009.html, Agustus 2018.

[6] T. Nam and T. A. Pardo, "Conceptualizing smart city with dimensions of technology, people, and institutions," in Proceedings of the 12th Annual International Digital Government Research Conference on Digital Government Innovation in Challenging Times - dg.o '11, College Park, Maryland, 2011, p. 282.

[7] K. Su, J. Li, and H. Fu, "Smart City and the Applications," Electron. Commun. Control ICECC 2011 Int. Conf. IEEE, p. 4.

[8] U. Yudatama, K. Kunci, and K. Cerdas, "Pengukuran Penerapan Teknologi Informasi untuk Membangun Smart City," Konf. Nas. Sist. Inf. KNSI, p. 6, 2013.

[9] H. Gunawan, “Analisis Penerimaan Teknologi 'Smart City' Kota Purwokerto Dengan Model
Technology Acceptance Model (TAM)," Konf. Nas. Sist. Inf., p. 6, 2018.

[10] A. Amrullah and E. Utami, "Perancangan Sistem Informasi Pada Smart UMKM dalam Mendukung Sleman Smart Regency," Konf. Nas. Sist. Inf. KNSI, p. 7, 2018.

[11] Hudjolly, "Epistemologi dalam Kebijakan Publik: Kajian Konsep Smart City di Indonesia," Untirta Civ. Educ. J., vol. 2, no. 1, pp. 31-48, Apr. 2017.

[12] L. Mayangsari and S. Novani, "Multi-stakeholder co-creation Analysis in Smart city Management: An Experience from Bandung, Indonesia," Procedia Manuf., vol. 4, pp. 315-321, 2015.

[13] N. Fitri Kireina, "Mesin Parkir Elektronik sebagai Wujud dari Smart City di Kota Bandung," J. Ilmu Sos. Dan Ilmu Polit., vol. 7, no. 2, pp. 63-80, 2017.

[14] A. Coe, G. Paquet, and J. Roy, "E-Governance and Smart Communities: A Social Learning Challenge," Soc. Sci. Comput. Rev., vol. 19, no. 1, pp. 80-93, Feb. 2001.

[15] A. C. Triyandra, "Perencanaan Komunikasi Dinas Komunikasi, Informatika, Statistik dan Persandian Kota Pekanbaru dalam Mensosialisasikan Program Smart City," J. Online Mhs. Fak. Ilmu Sos. Dan Ilmu Polit. Univ. Riau, vol. 4, no. 2, p. 13, 2017.

[16] A. D. Pramuningrum and D. S. F. Ali, "Strategi City Branding Humas Pemerintah Kota Bandung sebagai Smart City melalui Program Smart Governance," J. Acta Diurna, vol. 13, no. 2, pp. 21-32.

[17] Z. Gill, "User-driven collaborative intelligence: social networks as crowdsourcing ecosystems," in Proceedings of the 2012 ACM annual conference extended abstracts on Human Factors in Computing Systems Extended Abstracts - CHI EA '12, Austin, Texas, USA, 2012, p. 161.

[18] C. Webster et al., "User-Driven Collaboration for NASA Mission Control," in 2012 45th Hawaii International Conference on System Sciences, Maui, HI, USA, 2012, pp. 702-711.

[19] S. H. Supangkat, A. A. Arman, R. A. Nugraha, and Y. A. Fatimah, "The Implementation of Garuda Smart City Framework for Smart City Readiness Mapping in Indonesia," p. 8.

[20] E. F. Z. Santana, A. P. Chaves, M. A. Gerosa, F. Kon, and D. S. Milojicic, "Software Platforms for Smart Cities: Concepts, Requirements, Challenges, and a Unified Reference Architecture," ACM Comput. Surv., vol. 50, no. 6, pp. 1-37, Nov. 2017.

[21] J. H. Lee, R. Phaal, and S.-H. Lee, "An integrated service-device-technology roadmap for smart city development," Technol. Forecast. Soc. Change, vol. 80, no. 2, pp. 286-306, Feb. 2013.

[22] M. Janssen, Y. Charalabidis, and A. Zuiderwijk, "Benefits, Adoption Barriers and Myths of Open Data and Open Government," Inf. Syst. Manag., vol. 29, no. 4, pp. 258-268, Sep. 2012.

[23] H. Hielkema and P. Hongisto, "Developing the Helsinki Smart City: The Role of Competitions for Open Data Applications," J. Knowl. Econ., vol. 4, no. 2, pp. 190-204, Jun. 2013.

[24] A. Ojo, E. Curry, and F. A. Zeleti, "A Tale of Open Data Innovations in Five Smart Cities," in 2015 
48th Hawaii International Conference on System Sciences, HI, USA, 2015, pp. 2326-2335.

[25] M. P. Rodríguez Bolívar, Transforming city governments for successful smart cities. 2015. 